\title{
Didactical Framework for the Simulation of Computer Performance Analysis
}

\author{
David L. La Red Martinez (PhD) \\ Carlos A. Romero (Gra) \\ Northeastern National University, Argentine \\ Alice R. Rambo (Eng) \\ Misiones National University, Argentine
}

doi: 10.19044/esj.2016.v13n3p18 URL:http://dx.doi.org/10.19044/esj.2016.v13n3p18

\begin{abstract}
In this paper, we discussed the main aspects of the various development carried out on the subject of "Operating systems" and "Evaluation systems of data processing" for the degree course in information systems of the FaCENA from the UNNE. Here, emphasis was placed on various algorithms for the analysis of performance in calculation systems. The motivation for the realization of this work is based on the fact that students often encounter difficulties in identifying the formula that should be used in each of the statements of the practical exercises during performance analysis. The proposal aims to provide students with a tool to complement the developed in class. It was a web application designed to encourage the process of teaching - learning, based on an applet that acts as a container in using different interfaces. Each one of them represents the execution of a method of evaluation of performance, including the law of Amdhal, performance, improvement, comparative analysis, operational analysis, workload characterization, and capacity planning. In addition, a web application that allows the self-assessment of student in achieving learning outcomes was developed. The implementation of web application, however, makes use of the b-learning, model of teaching and learning combined, that collects the advantages of the model to distance. It also takes advantage of the importance of the group, the rhythm of learning, and the direct contact with the Professor.
\end{abstract}

Keywords: Operating systems, performance assessment, modeling for analysis of performance, simulation, systems of computations 


\section{Introduction}

In this work, we commented on the main aspects of development carried out on the subject of "Operating systems" and "Evaluation systems of data processing" for the degree course in information systems of the FaCENA from the UNNE. Here, emphasis was placed on various algorithms for the analysis of performance in calculation systems. It should be noted that the staged development is available to other subjects and other universities.

In the above-mentioned subjects, it has been detected that there are difficulties students experience in order to identify the formula that should be used in each of the statements of the practical exercises on performance analysis. Therefore, the proposal aims to provide students with a tool to complement the developed in class and the material provided by the university chair.

It has been made a web application that was designed to encourage the process of teaching - learning, based on an applet that acts as a container for use in different interfaces. Each one of them represents the execution of a method of evaluation of performance, including law of Amdhal, performance, improvement, comparative analysis, operational analysis, workload characterization, and capacity planning (Molero et al., 2004; Puigjaner et al., 1995).

In addition, a web application that allows the student to self-assess the acquired learning was developed. The implementation of the web application makes use of the b-learning (Bartolomé, 2004; Bersin, 2004; Bonk \& Graham, 2005; Taylor \& Newton, 2012; Turpo, 2010) and the teaching model of blended learning, which includes the advantages of model distance. Also, it takes advantage of the importance of the group, the pace of learning, and the direct contact with the teacher's classroom teaching (Heinze \& Procter, 2004; Heinze et al., 2007; Silva-Peña et al., 2014).

However, both e-learning and b-learning (Marsh et al., 2003) are models of learning in which the student has to develop important skills for their future life. This includes searching and finding relevant information on the internet; developing criteria to assess this information according to quality indicators; applying information to the development of new knowledge and situations of real-life; teamwork to sharing; and developing information to make decisions on the basis of verified information and based on a group. A student listening to the teacher usually does not develop these skills. On the other hand, the teaching model does not support the development of these skills. The blended learning model also encourages the development of these competences as part of the learning process.

One of the technologies used in the b-learning systems makes use of easiness provided by the Java language obtained from Web browsers. Thus, 
these facilities are specially supported by the applet (Deitel \& Harvey, 2008), which have been used in the development of software object to this article. In addition, it has been organized in the following manner: section 2 will indicate the methodology and the tools used; section 3 will describe briefly (for space reasons) the developed product; and section 4 will present the conclusions and future lines of work ending with references.

\section{Methodology and Tools Used}

The development methodology has been the incremental evolutionary. It is convenient to choose a process model designed to produce software incrementally. This is done in cases where the initial requirements of the software are well defined in a reasonable manner. However, the overall approach of the development effort excludes a purely linear process (Pressman, 2010). On the other hand, it may be the case also of an imperative need to quickly provide a limited set of functionality of the software.

The identification of services for the system along with a prioritization of them, made by the client, defined the iteration that would provide a subset concerning the functionality of the system (Sommerville, 2005). The first iterations are incomplete versions of the final product. Nevertheless, it provides the user with the functionality he/she needs and a platform to evaluate it.

Subsequently, the development is organized into a series of short, fixed length mini-projects, called iterations. The result of each shows a system that can be tested, integrated, and executed. Each iteration includes its own activities based on the analysis of requirements, design, implementation, and testing (Larman, 2005).

The selection of tools has been divided into two stages. The first stage is aimed at the construction of the integrated applet which in turn is the container of all the developed algorithms. This first stage serves as an environment for NetBeans IDE and programming language Java with JFreeChart for the graphics.

The second stage consisted of the creation of the web questionnaire in PHP with MySQL database. Through this web questionnaire, the student can undergo self-assessment of the dictated content by answering a set of questions.

Consequently, the tools that have been used for the creation of various applications, database, local server, and encoding include the following programs: StarUML, MySQL, PhpMyAdmin, XAMMP, Dreamweaver, Sublime Text, and the following programming languages; PHP, CSS, and Javascripts. 
This project was divided into three stages. The first stage consists of the bibliographic compilation and the study of different algorithms. The second stage involves the construction of the applet to integrate all the algorithms in order to motivate students to have the content ordered by methods. The third stage consists of the development of a web questionnaire, which allows the student to carry out self-assessment of their learning process. Additionally, at this stage, the applet and the questionnaire were integrated into a web site.

The following occurs during Stage 1:

- $\quad$ Survey of information and examples of systems developed in the web.

- $\quad$ Deepening of the theoretical framework. This was consulted as a source of data to document and as tools of the subjects "operating systems" and "evaluation and processing of data." Similar works, theses, and people with expertise in the design of applet didactic were also consulted.

- $\quad$ Study and assessment of the most important difficulties that arise in students in order to understand the theoretical content.

- $\quad$ Selection of the most important theoretical content to be taken into account.

Stage 2 was divided into the following sub-stages:

Sub-Stage 1: Analysis of the Sub-system of Methods

- Selection of information referred to the methods that are implemented include:

o Amdhal law.

o Performance.

o Improvement.

o Comparative analysis.

o Operational analysis.

o Workload characterization.

o Capacity planning.

- $\quad$ Analysis of Algorithms: Here, we studied the behavior of each one of them through practical exercises.

- $\quad$ Specification of Interfaces: This describes the benefits that should be met such as:

o Display formulas and concepts used in the calculations.

o Provide a help line.

o Graphically display the results.

Sub-Stage 2: Design of the Sub-system of Methods

- $\quad$ Design of menus used.

- $\quad$ Editing and location of the formulas.

- $\quad$ Design of graphics and text reports. 
- $\quad$ Design of interfaces for the different methods.

- $\quad$ Design emerging descriptions (help tooltips) for different methods.

Sub-Stage 3: Development of the Sub-system of Methods

- $\quad$ Development of the main menu.

- $\quad$ Adaptation of the images that would be included in the interfaces.

- $\quad$ Development of the representative graphics for each result.

- $\quad$ Development of interfaces in the java language.

- $\quad$ Creation and insertion of the tooltips to interfaces.

- Union of the interfaces within the menu main.

Sub-Stage 4: Implementation of the sub-system of methods

- $\quad$ Testing and validation of the application.

- $\quad$ Final implementation of the application.

Furthermore, stage 3 has been divided into the following sub-stages:

Sub-Stage 1: Analysis of the sub-system of self-assessment

- $\quad$ Study of b-learning systems and self-assessment features.

- The theoretical discipline content selection which is specific to be included in the questionnaire of self-evaluation (topics, questions, and answers).

- $\quad$ Definition of the reaches of the sub-system and their functionalities.

- $\quad$ Selection of Tools: The tools which have been used for the creation of various application, database, local server, etc. include the following programs: Dreamweaver, Sublime Text, XAMMP, MySQL, PhpMyAdmin, StarUML, and the following programming languages; PHP, CSS, and Javascripts.

- $\quad$ Realization of the use of Case Diagrams: The set of use cases and actors was shown (an actor can be either a system or a person). Also, their relationships shows who can do what and the relationships that exist between the various actions. The functionality of the system is modelled grouping in the descriptions of actions carried out by a system to obtain a result.

- $\quad$ Preparation of Tables of Conversation: The use cases are documented with informal text known as description of use case or conversation. It refers to a numbered list of steps followed by the actor in order to interact with the system.

- $\quad$ Generation of Sequence Diagram: It shows the interaction of a set of objects in an application over time, and it must employ one of this for each use case.

Sub-Stage 2: Design of the Sub-system of Self-assessment

- Definition of Profiles

o Student.

o Professor.

o Administrator. 
- $\quad$ Interface Design

o Design of the interface for the student's profile.

o Design of the interface for the teacher's profile.

o Design of the interface for the Administrator's profile.

- $\quad$ Design of Data Model: The data model that was designed contains nine (9) tables.

Sub-Stage 3: Development of the Sub-system of Self-assessment

- Development of Interface for Profiles

o Student.

o Professor.

o Administrator.

- Development of the Application.

Sub-Stage 4: Implementation of the Sub-system of Self-assessment

- $\quad$ Testing and validation of the application.

- $\quad$ Final implementation of the Software Application.

\section{Product Developed}

The developed web application consists of two modules. They are:

- $\quad$ User module.

- Administration module.

The user module is composed of two sub-modules:

- $\quad$ Sub-models of learning.

- $\quad$ Sub-models of self-assessment.

The sub-models of learning include the following topics (Figure 1):

- Amdhal law.

- $\quad$ Performance.

- Improvement.

- $\quad$ Comparative analysis.

- $\quad$ Operational analysis.

- Workload characterization.

- $\quad$ Capacity planning. 


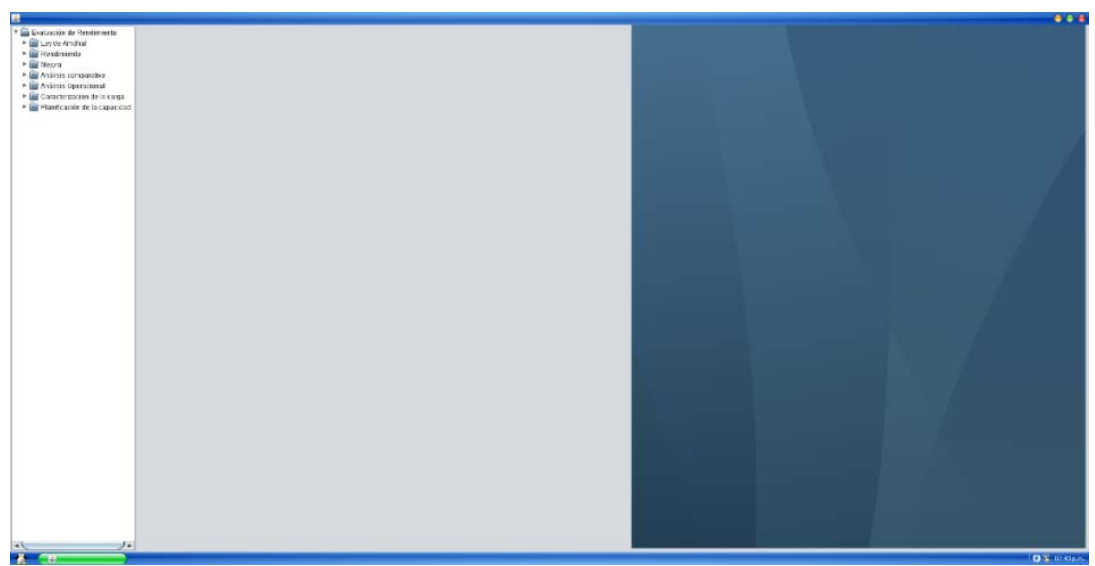

Figure 1. The sub-models of learning options

Source: Own elaboration.

Taking into account the way of managing data entry and displaying the results, it is possible to separate the topics that was referred to into two groups:

First Group

- Amdhal law.

- $\quad$ Performance.

- Improves.

The first group is structured in the following ways: Here, the user sees the display of the corresponding formula and textboxes for the input data. Results, both in graphical form and as text, are displayed in the same window. It is also possible to access a small guide to help in an interactive way with the mouse position. For example, if the user moves the mouse to a text box, it would display a small window that indicates the type of data that is allowed to enter (Figure 2).

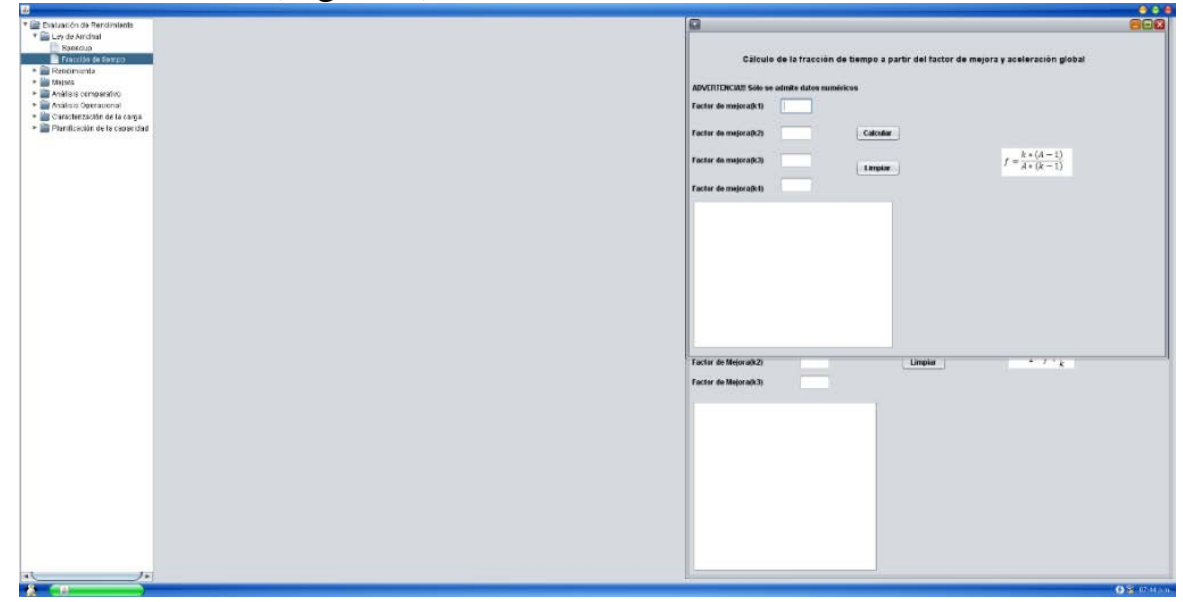

Figure 2. Option Amdhal law for a fraction of the time.

Source: Own elaboration. 


\section{Second Group}

- $\quad$ Comparative analysis.

- $\quad$ Operational analysis.

- Workload characterization.

- $\quad$ Capacity planning.

In the second group, each window contains a few tabs. The formulas are displayed on the first. The second contains the matrix in which the data required for the calculations are loaded. Finally, it has tab where the results are obtained. If the position of the mouse is moved over the area of interest, for example over a button, an aid appears that shows what must be entered or the action needed to be performed (examples is shown in Figure 3, Figure 4, Figure 5, and Figure 6).

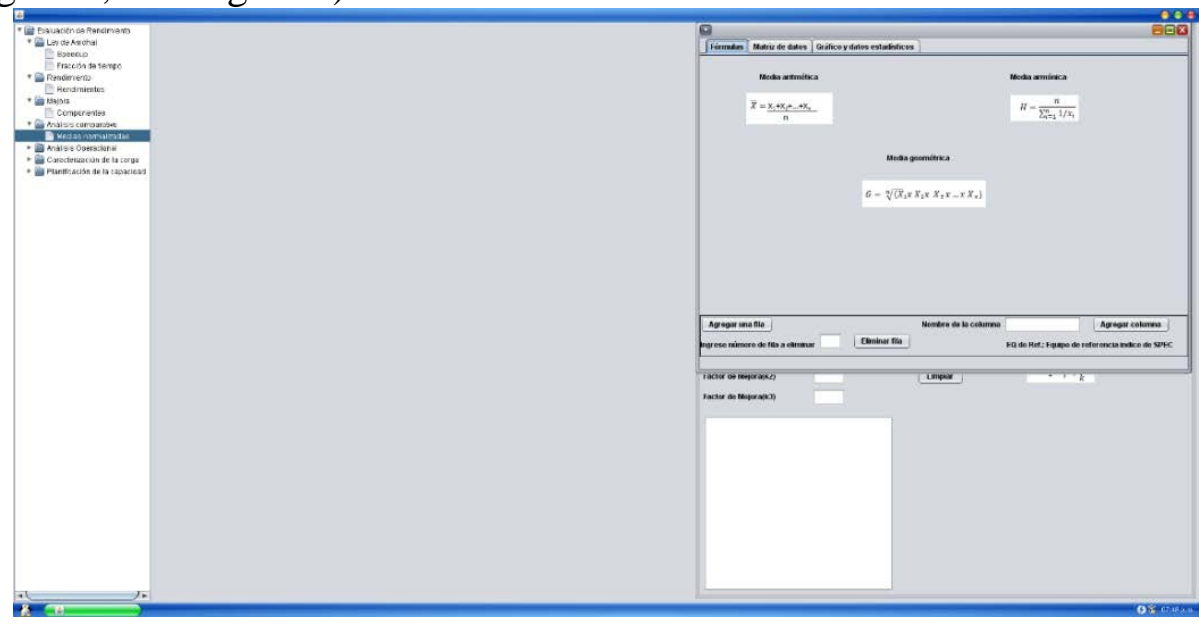

Figure 3. Comparative analysis with standardized average option Source: Own elaboration.

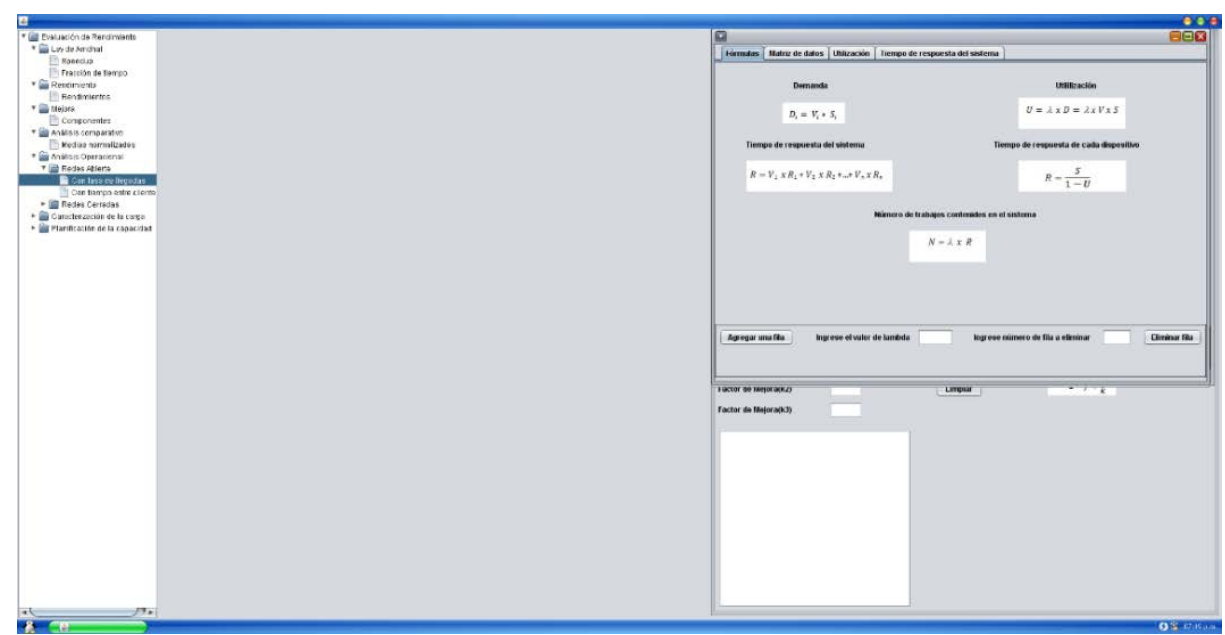

Figure 4. Option operational analysis for networks with rates of arrivals Source: Own elaboration. 


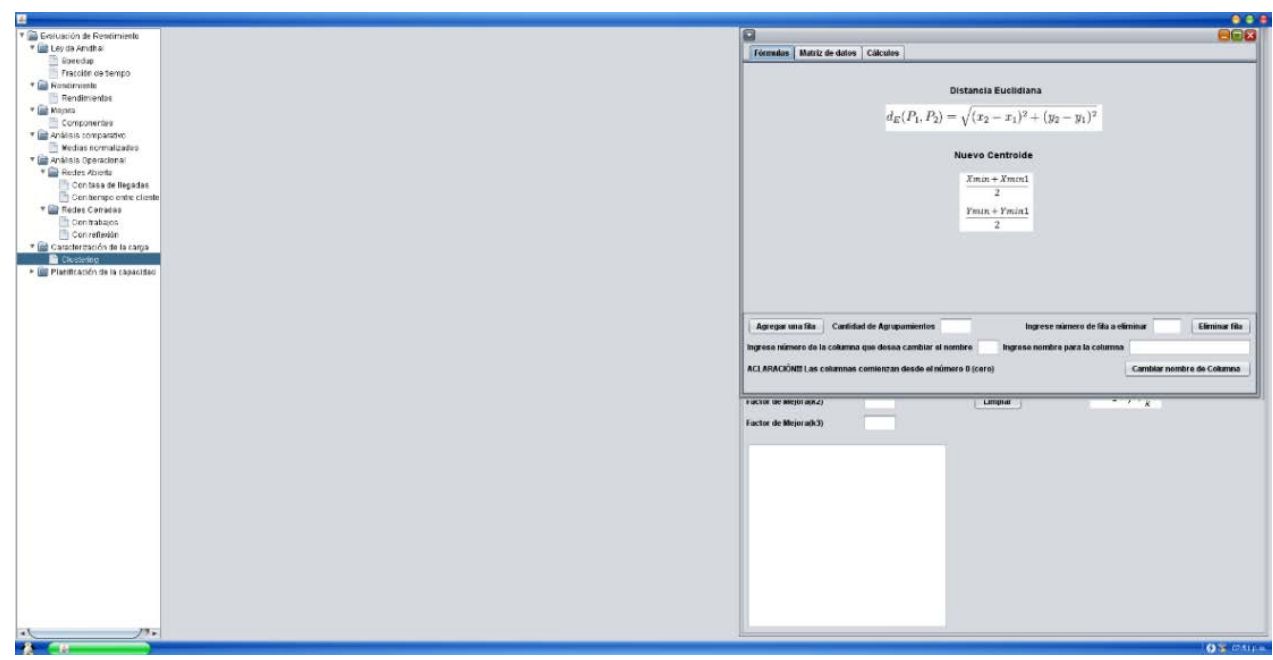

Figure 5. Characterization of the load with clustering option Source: Own elaboration.

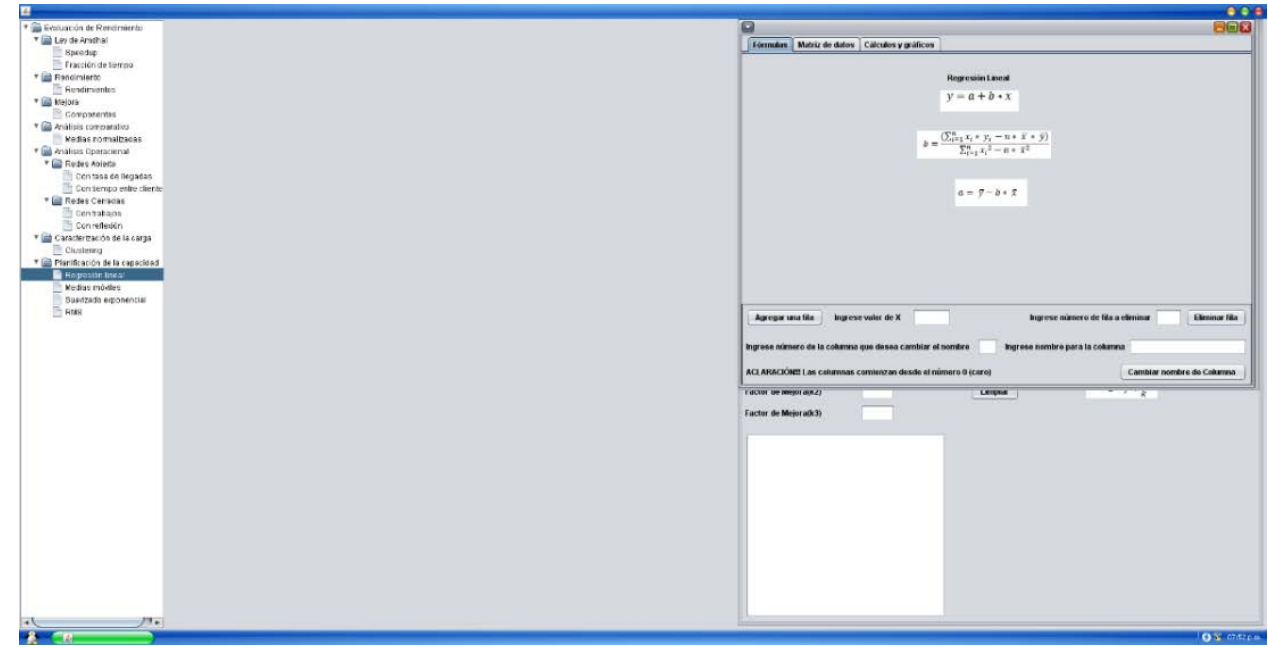

Figure 6. Option with linear regression capacity planning Source: Own elaboration

In the context of this work, the following concepts were considered:

- $\quad$ Performance Evaluation: A simple way to compare the returns of different computer systems is to use the runtime of a program or, more typically, a suite of programs as a performance measure. These programs represent the test load that will assist in building the results of the comparative study.

- Amdhal Law: It defines the gain in performance and Acceleration (speedup) which can be achieved when using a particular feature.

- $\quad$ Comparative Analysis of the Performance: Any matter involving the measurement of the performance of a team and a subsequent comparison 
with other systems will result, inevitably, in very controversial opinions. The current trend within the field of the evaluation of performance is mainly oriented in using indexes. This, however, takes into account the execution time in a team on a set of test or assessment (benchmarks) programs.

- $\quad$ Operational Analysis: The operational analysis is part of a series of techniques known as analytical. It is employed in the estimation of the performance of computer systems. These techniques make use of a model of behavior of the equipment and its load. Also, the indexes of benefits from this model were calculated.

- Clustering Technique: The analysis through clustering is a mathematical technique for grouping measurements, events, and individual works that are similar in some aspect or in some way. These works are described using the numerical values of a set of parameters, such as the used processor time, the number of input/output operations of the different peripherals, the memory required for the execution, etc. The choice of the parameters used to characterize these work is important and it depends on the purpose for which the model was built.

- $\quad$ Capacity Planning: Capacity planning notes the business needs that must be satisfied. Also, it helps in understanding and analyzing the workloads that are to be run, the service (response time) to be provided, and it details the physical resources (capacity) that is required.

Subsequently, the Administration module is composed of two submodules:

- $\quad$ Administrator sub-module.

- $\quad$ Professor sub-module.

In the Administrator sub-module, you have the possibility to enter the username and password. If the user that inputs his/her data is an administrator, then he/she has the possibility to enter two sections:

- Charge.

- Users.

In the teaching position section, the administrator can add, edit, and delete a role. The same is used to differentiate the teachers. Once it is inside view, it has a list of all teaching positions that were already added. Also, it has the possibility of performing a search (examples is shown in Figure 7 and Figure 8).

In the user's section, three profiles can be enlisted:

- Teachers.

- $\quad$ Students.

- Administrators.

The student's registration is performed by the administrator through the official list that was registered based on the subject. Therefore, this 
makes it unnecessary for a specific module based on the registration of students and the users of the system.

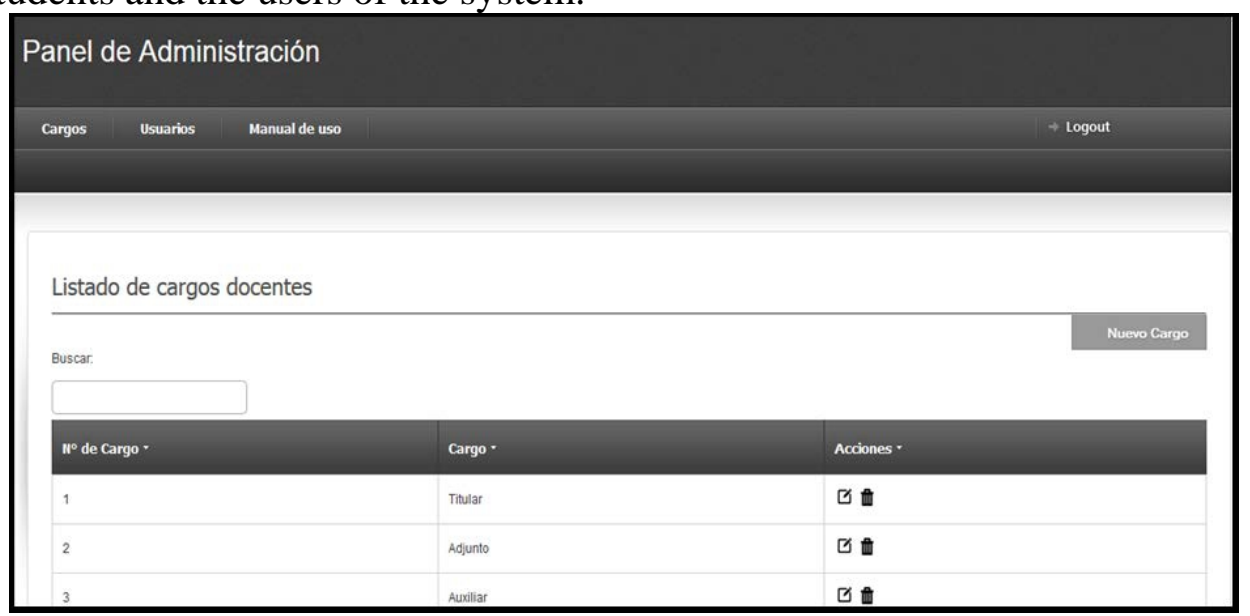

Figure 7. List of teaching positions

Source: Own elaboration

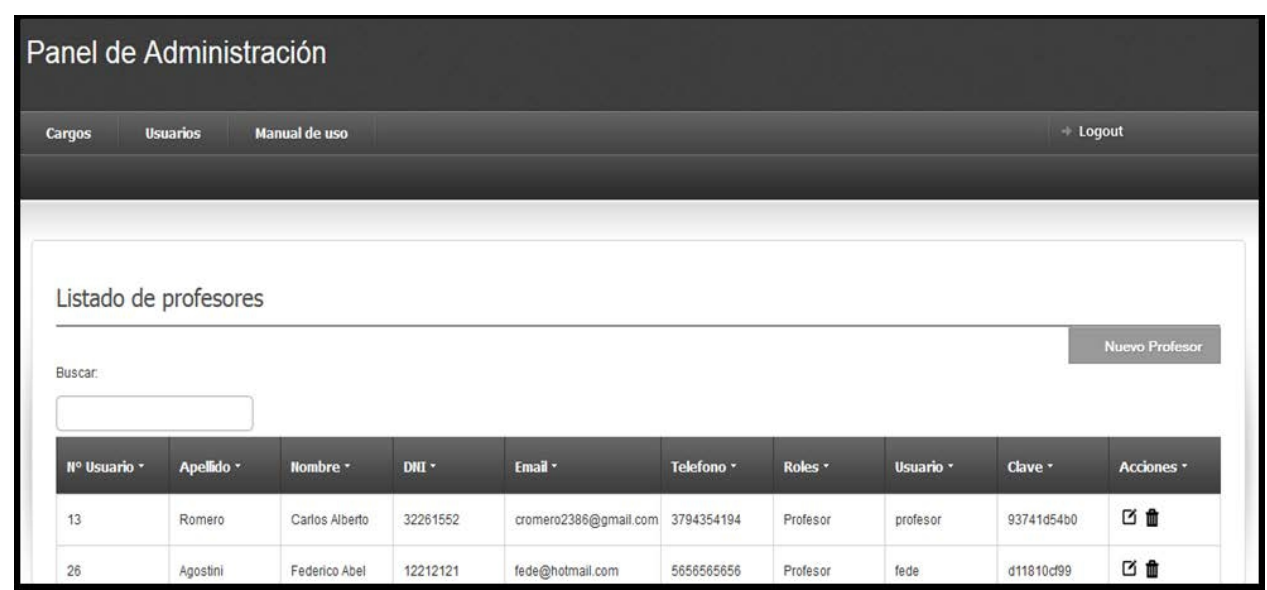

Figure 8. List of teachers

Source: Own elaboration

Creating profiles are always in the same way in all cases. Next, it explains one of them (teachers): When the entering displays the corresponding listing whereby you can add, edit and delete, it also has the possibility to perform a search.

The sub-modules of teachers entail the possibility of joining three sections:
- $\quad$ Self-assessments.
- $\quad$ Historical students.
- $\quad$ Reports.
- $\quad$ Self-assessments 
In the section on self-evaluations, the teacher can add, edit, and delete questions. Furthermore, you can also search textual (Examples is shown in Figure 9 and Figure 10).

The historic section of pupils displays the list of all the students that entered the system and can also be used to conduct searches textual (example is shown in Figure 11).

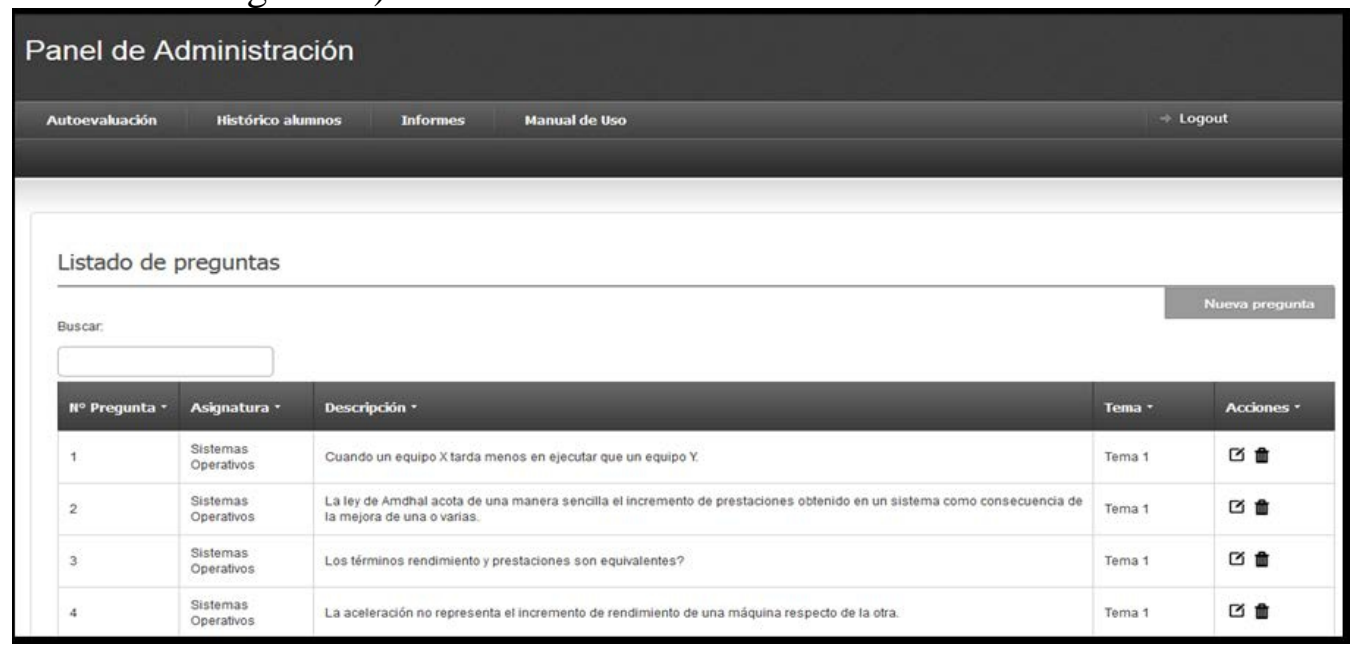

Figure 9. List of questions

Source: Own elaboration.

\section{Análisis de Rendimiento en Sistemas de Cómputos - Evaluación}

En Unix el uso de sistemas de ficheros se puede examinar mediante la orden di.

CVerdadero

CFalso.

Figure 10. Questions for evaluation

Source: Own elaboration 


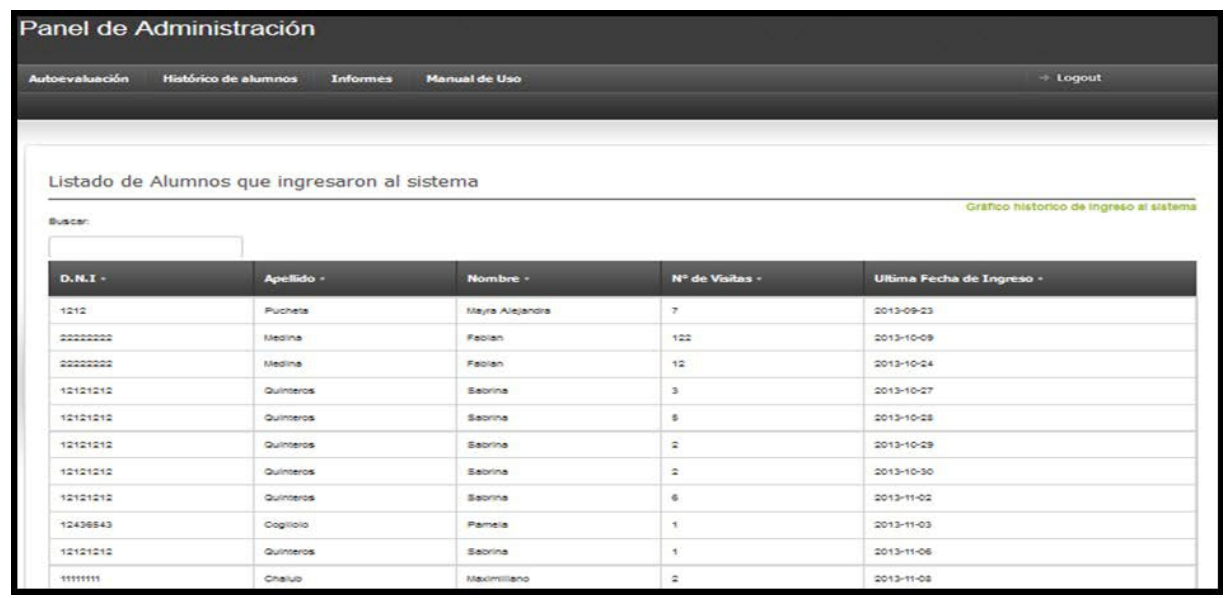

Figure 11. Income for assessment

Source: Own elaboration.

However, this section of reports shows the following:

- $\quad$ Registered students.

- $\quad$ List of administrators.

- $\quad$ List of teachers.

- $\quad$ List of admission of students.

When someone clicks on some of the above options, a tab opens a file in PDF format, which is ready to be printed or to be saved.

\section{Conclusion and Future Work Lines}

Conclusively, the various tools have been integrated in a very satisfactory manner during the performance of this work.

It provided different interfaces in accordance to each one of the algorithms to facilitate the process of understanding simple ways of the execution and results. Hence, it helps in the achievement of the proposed objectives.

In addition, it includes a self-assessment method for the student, and you can evaluate yourself by means of a questionnaire that is randomly generated based on a theoretical-practical content of the different topics. These topics are related with the simulations provided through the web application.

The methodology developed can be transposed to other areas of knowledge which is applicable to the b-learning. Here, it is deemed appropriate to combine simulations with calculations, graphics, and the possibility of self-assessment.

Based on future lines of work, it will seek to expand the group of algorithms implemented and analyze new mechanisms of self-assessment to facilitate the process of self-learning. 


\section{References:}

1. Bartolomé, A. R. (2004). Blended Learning. Conceptos básicos. En Pixel-Bit. Revista de Medios y Educación, 23, 7-20.

2. Bersin, J. (2004). The Blended Learning Handbook: Best Practices, Proven Methodologies, and Lessons Learned. Pfeiffer Wiley. ISBN 0-7879-7296-7.

3. Bonk, C. J. \& Graham, C. R. (2005). The Handbook of Blended Learning: Global Perspectives, Local Designs. Pfeiffer Wiley. ISBN 0787977580.

4. Deitel, P. J. \& Harvey, M. D. (2008). Como Programar en Java. Séptima Edición. Pearson Educación. Mexico.

5. Heinze, A. \& Procter, C. (2004). Reflections on the Use of Blended Learning. Education in a Changing Environment conference proceedings. University of Salford, Salford, Education Development Unit.

6. Heinze, A.; Procter, C. \& Scott, B. (2007). Use of Conversation Theory to underpin Blended Learning. International Journal of Teaching and Case Studies 1(1 \& 2): 108-120.

7. Larman, C. (2005). UML y Patrones. Una Introducción al análisis y diseño orientado a objetos y al proceso unificado. Prentice Hall. España.

8. Marsh, G. E.; McFadden, A. C.; \& Price, B. (2003). Blended instruction: Adapting conventional instruction for large classes. Online Journal of Distance Learning Administration, vol. $6 \mathrm{n}^{\circ} 4$.

9. Molero, X.; Juiz, C.; \& Rodeño, M. (2004). Evaluación y Modelado del Rendimiento de los Sistemas Informáticos. Pearson Educación. España.

10. Pressman, R. S. (2010). Ingeniería del Software, Un Enfoque Práctico. 7ma Edición. McGraw-Hill. Mexico.

11. Puigjaner, R.; Serrano, J. J.; \& Rubio, A. (1995). Evaluación y explotación de sistemas informáticos. Editorial Síntesis. Madrid.

12. Silva-Peña, I.; Salgado-Labra, I.; Verdugo, C.; \& Chehuaicura, A. (2014). Aprendizaje Colaborativo en un módulo de formación docente basado en Blended Learning. Foro Educacional, (21), 127143.

13. Sommerville, I. (2005). Ingeniería del software. 7ma. Edición. Pearson Addison Wesley. España.

14. Taylor, J. \& Newton, D. (2012). Beyond blended learning: A case of institutional change at an Australian regional university. Internet and Higher Education, 18, 54-60. 
15. Turpo, O. (2010). Contexto y desarrollo de la modalidad educativa blended learning en el sistema universitario iberoamericano. Revista Mexicana de Investigación Educativa. 15(45), 345-370. 